\title{
ろう付け充填層の静止時有効熱伝迸度についで*
}

\author{
武 岡 壮**.西 村 靖 彦**
}

\section{Stagnant Effective Thermal Conductivities of Soldered Packed-bed*}

\author{
S. Takeoka** and Y. Nishimura**
}

Stagnant effective thermal conductivities of soldered packed-bed $\left(k_{0}{ }^{\circ}\right)$ for sphere packing were measured by the method which is ordinarily used for metal rod. Values of $15 \sim 28 \mathrm{kcal} / \mathrm{m} \cdot \mathrm{hr} \cdot{ }^{\circ} \mathrm{C}$ were obtained for soldered packed-bed made by soldering iron and brass sphere with pewter.

The $k_{0}{ }^{\circ}$ of soldered packed-bed has been measured to be independent of the orientation of heat flux, since the distribution of bridge-parts which connect the spherical packings of soldered packed-bed to each other, was uniform throughout the whole surface of the sphere.

A theoretical estimation of the stagnant effective thermal conductivity was tried as follows.

At first, the resistance of thermal conduction was estimated on two spherical packings connected to each other with solder and then a correction was introduced. In soldered packed-bed heat will be conducted along a long zig-zag roundabout way. The ratio of the length of zig-zag path to the straight distance was named effective path length coefficient $(\alpha)$. The resistance of thermal condution should be multiplied $\alpha$-fold of that of the first model.

Three regular types of sphere packing values of $\alpha$ were calculated, and it was found that $\alpha$ has a simple linear functional relation with the void fraction of soldered packed-bed.

$$
\alpha=0.85+1.18 \varepsilon
$$

Thus $k_{e}{ }^{0}$ may be estimated by the following equation,

$$
k_{0} 0=(1-\varepsilon) \frac{3}{\alpha \Omega} k_{p}
$$

The agreement between calculated and obserbed $k_{0} 0^{\circ}$ was very good.

\section{1. はじめに}

前報告1)でろ5 付け充填周の半径方向の静止時有奻熱 云尊度を一応の目安として, 充填層の $k_{0}{ }^{\circ}$ 测定法の一種 を参考として測定したが，その後実験法が不適当なこと が判明したので，今回は金属棒の熱云導度の测定法2)を 用い，層の軸方向の温度分布により $k_{0}{ }^{0}$ を求めた。 従来多孔質物質の研究は耐火物网係で Leob, Eucken らが輻射の影票を考して行ない，充填層では1938 年 Kling ${ }^{3)}$ の $k_{\text {。 }}$ 研究以来非常に多くの研究があり， $k_{0}^{0}$ に 関してる20籍に近く，伝热機棈を考察したものでも

\footnotetext{
* Received on April 9, 1962

** 哽京工萧大学化学工学科 Dept. of Chem. Eng., Tokyo Institute of Technology
}

Wilhelm"), Smith ${ }^{5)}$ ，矢木 - 国井(5)，Kunii，D. \& Smith, J. $\mathrm{M}^{7}$., Schotte ${ }^{8)}$, 杉山・藤津 ${ }^{9}$ などあり，よく研 完されている。この内ろ5付け充填首に最す近い系は Kunii, D. \& Smith Kよる砂岩中焼結金属に対する研 究であるか，固化した粒子としないそれとが混在して充 填されているモデルを用いているので空間事が大きくと す全体が一体となっているこの屏では別のモデルが必要 である。よって筆者らは新たにこの系について $k_{0}{ }^{\circ}$ の推 算を試み良好な結果を得た。

\section{2. 实駼方法，装是よよひ式料}

実験装䐈を Fig. 1 に示す。軟鋼製円简容器 (1) 内に隔 壁 (2)を設け，その中に伝熱試聒ブロックを入れ，その 隌间を珪鿓土でののように埋めて保温し，そのつど理 
藻土をかき出す。伝熱ブロックの下部 (3は, $50 \mathrm{~mm}$ 径 $\times 90 \mathrm{~mm}$ の軟鋼塊で, 周囲をニクロム線 (4) で加熱す る。(5がろう付け充填層で，ここに 70 120 $\mathrm{mm}$ の距 離に®のことく 4 本の $0.3 \mathrm{~mm}$ の銅一コンスタンタン 熱電対を溶接してある。⑥は $99.97 \%$ 純度の電解鉄丸 棒で, $100 \mathrm{~mm}$ 間隔に $2 \mathrm{~mm}$ 径の穴を棒の中心部までら がち、ここと熱電対を挿入してある。最上部 (0は水冷 ジャケットである。(5とのはとすに $40 \mathrm{~mm}$ 径で, こ れらの軸方向の温度傾斜と (6の熱伝導度とから $k_{\bullet}{ }^{\circ}$ を らる。

試料の製作法は，まず (6 を倒立させ，その上面に内 径 $40 \mathrm{~mm}$ のガラス管をおき，その中に融解ろう材に浸 して引上げた充填物をそのまま充填し，さらに上部より ろろ材を注いで行な5。融解ろろ材はガラス管と丸棒の すきまりり流下し去る。ついで命却固化後ガラス管をと り除き，空間事をはかっでく。ついで銅ブロック (3) を熱し、 (3の上部にある深さ $7 \mathrm{~mm}$, 径 $42 \mathrm{~mm}$ の円形 の凹みに融解ハンダを半ば充し置き，さきに製作した6 と(5よりなる円柱を(7)が上になるよ5にし，これに $100^{\circ} \mathrm{C}$ の水蒸気を吹きつけて加熱した後凹みの中にひた

\section{し, 接続固化を特つ。}

伝熱則定は加熱㧍よび水冷開始後， 3 時間から翌日に 到る数回にわたり行ない平衡値に達したものを用う。 $k_{e}{ }^{0}$ は 2 組の平均として求めてある。熱電対の電位差は

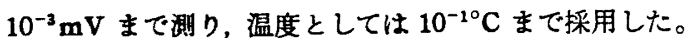

製作試料の充填物として銅球と真鍮球，ろら材として 鉛：錫=1：1の成分をむつハンダおよび錫，を用いた。

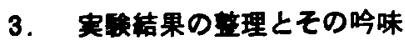

\section{$k_{\bullet}^{0}$ はつきの計算式}

$$
q=A \cdot k_{\mathrm{Fe}} \cdot \Delta T_{\mathrm{Fe}} / \Delta x_{\mathrm{Fe}}=A \cdot k_{\mathrm{e}} \cdot \Delta T / \Delta x
$$

より求め, 電解鉄の云尊度は（10）より

$$
1 / k_{\mathrm{Fe}}=5.744+2.432^{\circ} \mathrm{C} \quad\left(34^{\circ} \mathrm{C}\right)
$$

より算定した $k_{\mathrm{Fe}}=61.9 \mathrm{kcal} / \mathrm{m} \cdot \mathrm{hr} \cdot{ }^{\circ} \mathrm{C}$ を用いた。この 数值はさらに銅丸棒を $k \mathrm{cu}=320 \mathrm{kcal} / \mathrm{m} \cdot \mathrm{hr} \cdot{ }^{\circ} \mathrm{C}$ として 検定し，適当なことを認めてある。

得られた $k_{0}{ }^{\circ}$ を Table 1 の obsd. 椚に示す。 $k_{0}{ }^{\circ}$ の測 定值には材質の变化による增减があるが，球径による変 動は少ないと考えてよいであろう。

実験方法により明らかなよ それであり，半径方向の $k_{8}{ }^{0}$ と同様であるとの保証はな いが，畨を破壊した接着切口の定性的所見によればその 大きさにも分散にも方向性が認められないので, この場 合は $k_{0}{ }^{\circ}$ に方向による盖異はないと考える。球状充填物 以外の，たをえばラシヒリングなどをろら付け充填した

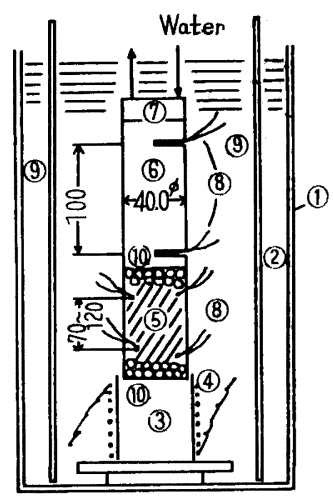
(1) steel vessel
() heating unit
(2) steel pipe
(B) soldered packed-bed
(4) nichrome wire
(7) cooling jacket
(0) copper-constantan thermocouple
(D) insulation (diatomaceous earth)
(1D) boundary zone

Fig. 1 The side view of experimental apparatus

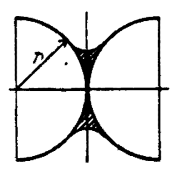

Fig. 2

A model of the soldered packed-bed

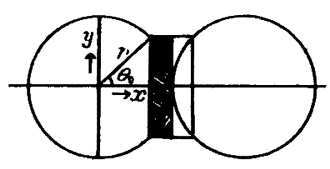

Fig. 3

A modified model of the soldered packed-bed
Table 1 Stagnant effective thermal conductivities of soldered packed-beds (sphere)

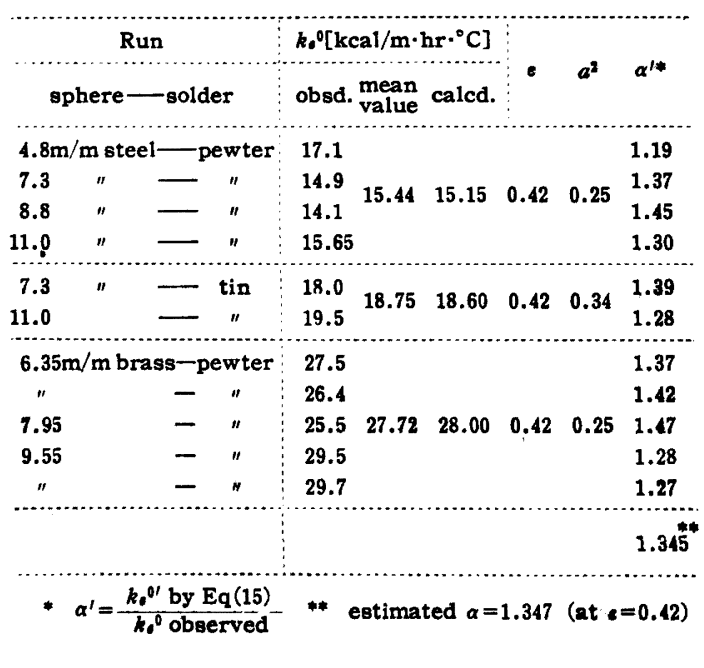




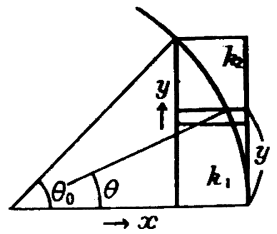

Fig. 4

A model of bridge section in the soldered packed.bed

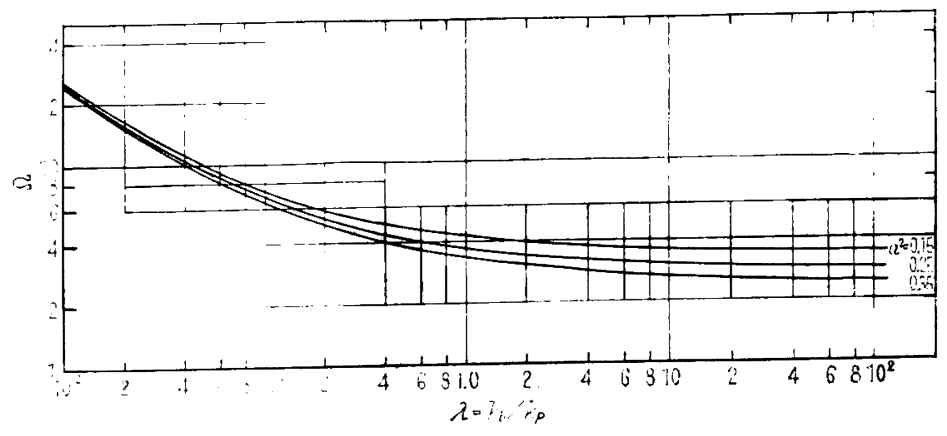

Fig. $5 \quad a-k_{b} / k_{p}$ diagram

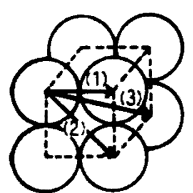

(a)

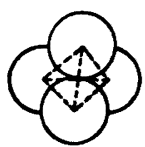

(c)

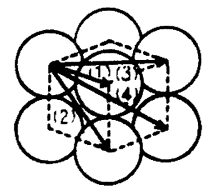

(b)

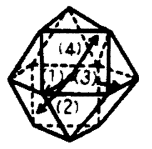

(c)'

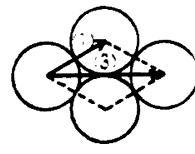

(b) ${ }^{\prime}$

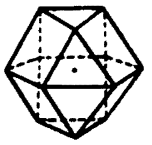

(c)"

(a) packing like a simple cubic lattice (loose packing)

(b) packing like a hexagonal lattice

(b)' a plane figure of (b)

(c) closest packing

$\begin{array}{ll}\text { (c) cubic closest packing } & \text { (c)" hexagonal closest packing }\end{array}$

Fig. 6 Three kinds of model packing

场合は静的ホールドフップ留留の仕方に方向による差 異があると考えられるので別途の考感が必要であろ5。 なおこの列定には試料の半径方向の䓡損失る存在する がその大きさが管軸方向の伝熟量の $1 \%$ 以下にゔぎな ので省略した。

\section{4. 理砱式の提察}

\section{1 理周式の望出}

ろろ付け充填首の觧止時の伝第機構を考えるにあた

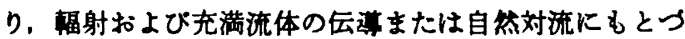
く云就径路は略す。数値的に㮔めて少ないと考えられる からである。考虑する场合は，充填層と全く同様にとり あつかえばよい。したがってこの場合伝熱壁，充填物固 体および接着部分の架㛢状の固体を順次径る伝留の径路 のみを考える。

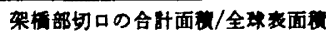

Fig. 2 に，2球のろら付けされた状態を示 す。斜線の部分を架橋部と呼ぼ 5 。この部分 は従来の静的ホールドフッブであるから曲面 で2球を連絡しており，その断面は円弧をる って近似し,ウェッジなどと呼ばれている11。

ここでは简単のために円弧のかわりに直線 を用い, Fig. 3 のことくらすい円板状の架 橋部を考える。ます最初に 1 この半球と架橋 部の半分 (Fig. 3 に斜線を引いた部分) をモ デルとし，それらの熱抵抗の和を求めてみよ 3。

各球には，約 6〜7 コの架橋部が表面にラ ンダムに分散している。これらの架橋部断面 を熱流方向に垂直な平面に投影させ，その面

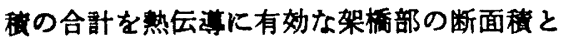
する。いま球の半径を $\boldsymbol{r}$ ，球の接着面積比* を $a^{2}$ とすると，半球上の架橋部を投影させ た面皘の合計は $\pi a^{2} r^{2}$ となる。この面積を熱流方向（x 軸）を中心とした円形にあつめて，再び Fig. 3 のこと きモデルを考える。この仮想架橋部の切口円の半径は arである。ここで四により明らかに，

$$
\begin{aligned}
& a r=r \sin \theta_{0} \\
& a=\sin \theta_{0}
\end{aligned}
$$

したがって接㴋面比を実測することにより仮想接触角 とす名付くでき $\theta_{0}$ が得られる。

（i） 半球部の熱抵抗 $R_{\mathrm{p}}$ を推算する。定常状態にお いて, フーリェの法則により熟云導は

$$
\begin{aligned}
& q=-k_{\mathrm{p}} A d t / d x \\
&-q \int \frac{d x}{k_{\mathrm{p}} A}=\int d t=\Delta t=-q \cdot R, \\
& R_{\mathrm{p}}=\int_{0}^{r \cos \theta_{0}} \frac{d x}{k_{\mathrm{p}} \pi\left(\sqrt{\left.r^{2}-x^{2}\right)^{2}}\right.} \\
&=\frac{1}{2 \pi r k_{\mathrm{p}}} \ln \frac{1+\cos \theta_{0}}{1-\cos \theta_{0}}
\end{aligned}
$$

（ii）仮想架嵊部の第抵抗 $R_{b}$ は，Fig. 4 のことく円 
板を同心管にわけたェレメントを考えて，これを通る熱 をठ无とすると

$$
\begin{aligned}
\delta_{q} & =2 \pi y \cdot \delta_{y} \frac{k_{p} \Delta t_{1}}{\sqrt{r^{2}-y^{2}-r \cos \theta_{0}}} \\
& =2 \pi y \cdot \delta_{y} \frac{k_{b} \Delta t_{2}}{r-\sqrt{r^{2}-y^{2}}}
\end{aligned}
$$

この架橋部は合せレンズのことく、異なった熱云導率の 球の一部と凹レンズ状物の 2 種の物質よりなるゆえ, 熱 流は一様ではないが，架檑全域にわたり， $\Delta t_{1}+\Delta t_{2}=\Delta t_{b}$ とすると、 $\lambda=k_{\mathrm{b}} / k$, と書換えて $\int \delta_{\mathrm{a}}$ を計算することに より,

$$
R_{b}=\frac{1}{2 \pi r k_{2}} \frac{\frac{\lambda-1}{\lambda}}{\left(1-\cos \theta_{0}+\frac{\lambda \cos \theta_{0}-1}{\lambda-1} \ln \lambda\right)}
$$

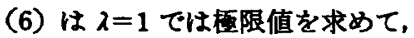

$$
R_{b}=\frac{1}{2 \pi r k_{p}}\left(\frac{2}{1+\cos \theta_{0}}\right)
$$

（iii）モデル全体の熱抵抗 $R$ は以上を合せて（4),

(6) より

$$
\begin{aligned}
R= & R_{p}+R_{b} \\
= & \frac{1}{2 \pi r k_{p}}\left[\ln \frac{1+\cos \theta_{0}}{1-\cos \theta_{0}}\right. \\
& \left.+\frac{\frac{\lambda-1}{\lambda}}{1-\cos \theta_{1}+\frac{\lambda \cos \theta_{0}-1}{\lambda-1}} \ln \lambda\right]=\frac{\Omega}{2 \pi r k_{p}}
\end{aligned}
$$

のを熱抵抗バラメーターとする。

$a^{2}$ を $0.15,0.25,0.35$ の 3 種にとり，(3)と（8）を 用いた入と $\Omega$ の計算図表を Fig. 5 に示す。

(iv) 径路保数 $\alpha$ 以上の半球モデルによる层熱推算 では，各球を伝熱方向に平行に直楾的に並べ，たた架橋 部のみを熱流方向に投影したモデルを考えている。実際 の云熱径路はジグザグに曲っているのであるから温度分 布も同様に曲っていよう。したがってこの㞒の云熱距離 は，全空間一様の伝熱を行な5と仮定した空間距離より 長くなっている。すなわち，ある長さの空間距離を熱が 移動するときの抵抗は, 伝熱径路がジグザクな曲り道で 長くなった比たけ大きい。この比を径路係数 $\alpha$ と名付け る。

aを推定するために, 規則的充填構造について, 僢在 2 球間の直線距離と，接触点を通ってジクザグ曲って の最短距離の比を求める。充填構造中の一球につき，そ の周囲にあるすへての隣在球に関して算定し，それらの 多くの径路の方向はその球を中心にして全方向に大体一 様に分散されているとしてその平均を求め，その粗造が

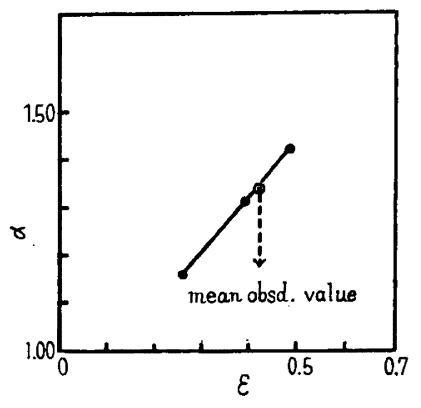

Fig. $7 \quad \alpha$ vs. $\bullet$

Table 2 Effective path length coefficients estimated by standard model of.

\begin{tabular}{|c|c|c|c|c|}
\hline \multicolumn{3}{|c|}{ closest packing } & \multicolumn{2}{|c|}{$c=26.0 \%$} \\
\hline & (1) & 1 & 1 & 12 \\
\hline \multirow{3}{*}{ (c) } & (2) & $\sqrt{2}$ & 2 & 6 \\
\hline & (3) & $\sqrt{3}$ & 2 & 24 \\
\hline & (4) & $\sqrt{6}$ & 3 & 8 \\
\hline
\end{tabular}
soldered packed-bed

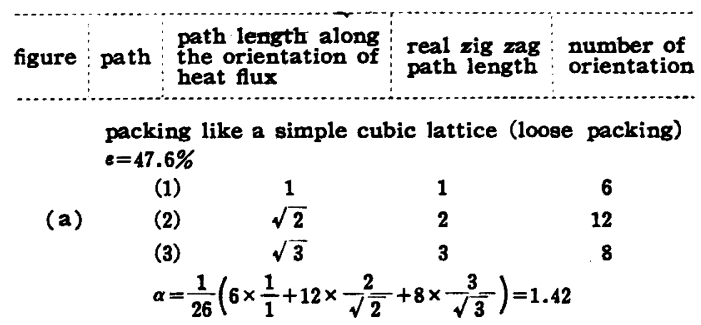

packing like a hexagonal lattice $e=39.5 \%$

(b)

$\begin{array}{lclr}(1) & 1 & 1 & 8 \\ (2) & \sqrt{2} & 2 & 12 \\ (3) & \sqrt{3} & 2 & 6 \\ (4) & 2 & 3 & 12\end{array}$

$\alpha=\frac{1}{38}\left(8 \times \frac{1}{1}+12 \frac{2}{\sqrt{2}}+6 \times \frac{2}{\sqrt{3}}+12 \times \frac{3}{2}\right)=1.31$

unit of path length $=D_{p}$

持つ $\alpha$ とする。

モデルとした 3 種の充填構造を Fig. 6 に示す。この 内（a）は，単純立方格子の角が各球の中心になってい る構造で、いわゆる Loose packing である。矢印が隣 在 2 球の直線距離を示す。たとえば（1）では，直線距 離と伝熱径路は等しい。(2) では, 直線距離は $\sqrt{2} D_{p}$, 直角に曲った伝熱径路は $2 D_{p}$ である。この要領で一球 に関し，すへての組合せを考える。(b) は六方格子の陵 の長さの等しいものであり，側面のつみ方は正方形で， 上面は (b)' のことく菱形になっているような充填粠造 を持つ。(c) はいわゆる最密充填棈造の 4 面体の単位を 示す。(c)'と(c)”は分子構造論によく知られた模型よ 


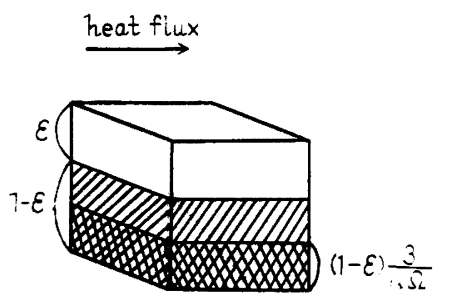

Fig. 8 Heat transfer model of soldered packed-bed

Table 3 Thermal conductivities of metals used in calculation

Metal

$h$

reference

standard pure iron 61.9 Kagaku-Kogaku-benran 1st. ed p. 120 copper

320 Kuzuoka-Kurita ; Dennetsukogaku

steel ball

brass ball

tin

pewter

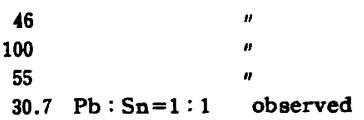

り借りたもので, つみ方は若干巽なるが空間率は同じで ある。この場合 $\alpha$ b同じに出る。計算の詳細を Table 2 に示す。このほかにも各種の規則充填满造はあるが,一 応敍上の 3 種を標準とし各 $\varepsilon$ と $\alpha$ をブロットすると Fig. 7 のことく大体直線関係がえられる。これは球の立 填様式が密になるに従って, 各球かより直楾的に並ふこ とを示す。 3 点を結ふ線を直線と仮定し,

$$
\alpha=0.85+1.18 \varepsilon
$$

をうる。ここでさらに一般の球充填ですをと $\alpha は （ 9 ）$ の関係にあると仮定する。（9）の適用箅井は球充填にお ける $\varepsilon=0.26 \sim 0.476$ である。

以上を総合して，ろろ付け充填周中の半球と仮想架棉 部の整抵抗の和 $R^{\prime}$ は，卮熟距甠をととすると。

$$
R^{\prime}=\alpha R=\frac{\alpha \Omega}{2 \pi r k_{p}}
$$

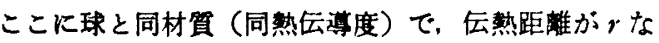
る熱抵抗 $R^{\prime}$ の円简を考え，その半径を $X$ とすると,

$$
R^{\prime}=\frac{r}{\pi X^{2} k_{p}}
$$

(10) と（11）より,

$$
X=\sqrt{\frac{2}{\alpha \Omega}} \cdot r
$$

この円简の体楼 $V$. 5 と半球および仮想架橋部の体䆏の 和との比は $V$ 中の仮想架檑部の体稓を略すと*,

$$
\frac{V_{\text {of }}}{V}=\frac{2 \pi r^{3}}{\alpha \Omega} / \frac{2 \pi r^{3}}{3}=\frac{3}{\alpha \Omega}
$$

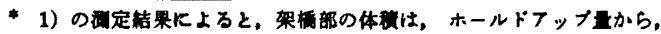

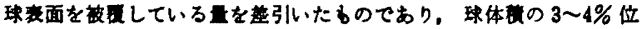
と宩えられる。
今 Fig. 8 のよ5な単位立方体のろう付け充填層を考党 るとき，(13）により，熟层尊有効断面程は，層固体が すへて球と同材質として，(1- $\varepsilon) \cdot 3 / \alpha \Omega$ に換算される。 したがって

$$
\begin{gathered}
q=(1-\varepsilon) \frac{3}{\alpha \Omega} k_{p} \cdot \Delta T=k_{\bullet}{ }^{\circ} \cdot \Delta T \\
k_{\bullet}^{0}=(1-\varepsilon) \frac{3}{\alpha \Omega} k_{p}
\end{gathered}
$$

を 5 る。

\section{$4 \cdot 2$ 実鈋結果との比就}

計算に必要な材質の熱伝導度表を Table 3 に示す。

$\varepsilon, a^{2}$ は測定結果の平均を用い，（3）ょり $\theta_{0}$ を，Fig. 5 より $\Omega$ を（9）または Fig. 7 より $\alpha$ を得, これらを （14）に導入して得た $k_{。}^{0}$ を Table 1 calcd. の楖に示す。 実測值は若干变動しているのでこれを球材質とろう材が 同じものにつき平均し， mean value 杣に示してある か，これと計算值は非常によく一致する。

また全測定値にわたる計算值と実测值の間の变動をみ

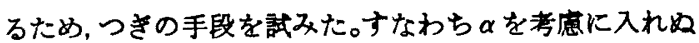

$$
k_{c}{ }^{\prime \prime}=(1-\varepsilon) \frac{3}{\Omega} k_{p}
$$

を各球とろう材の組合せにつき計算しておきこれを $k_{\text {。 }}^{0}$ 実測值で割り $\alpha^{\prime}$ とすると， $\alpha^{\prime}$ は, 各試料の径路係数 の变動を示す。径路係数は空間率ないし充填状態による としているので $\alpha^{\prime}$ の変動は，材質によらないから全測 定値に共通な变動である。この $\alpha^{\prime}$ を Table 1 の一概に 示す。若干の変功はあるが，その全平均は計算による $\alpha$ と非常によく一致している。

\section{5. 考璂}

緒需にものべたように，筆者らは前報告"において伝 熱量を測定して，半径方向の $k_{\bullet}^{0}$ を一応の目安として求 めたのであるが，後述のことく実稌方法が不適当であっ たと考える。

前報告における測定法ではジャケットを付した粮管内 の中心に外径約 $10 \mathrm{~mm}$ の鑐管をおき，内外管の间にろ 5 付け充填俨を作り内管に冷却水, ジーケット側に水蒸 気を疑䧽させ，冷却水の温度上年を以て伝等量とし，こ れより $k_{0}^{0}$ を求めた。その後の研究により冷却水と内管 内壁の间および球と内管外壁の間の熟抵抗がかなり大き いと想像されるに到った。

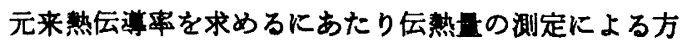
法は温度勾配の测定による方法に比較して不正磼とされ ている。前報で等者らは整定的目安として，総括伝熱㐿 数測定装度を流用して，一応求めたのであるが，それら は著しく逦小なるのであった。ろら付け充填間がこのよ 
万に大きな $k_{\bullet}{ }^{0}$ を有するとは全く予想しなかったため実 験法の吟味が不充分であった。今回は実験法の吟味とし て熱层導度既知の銅丸棒を測定し方法の適正なるを確訆 してある。ここに前報1の $k_{0}{ }^{0}$ の実験値を取消したい。 半径方向の $k^{\circ}$ の測定は大きな層試料を製作しなけれ ばならないと考えられるので今回は略した。

・これらの $k_{*}{ }^{\circ}$ はステンレスないし鉛の丸棒のそれに相 当する。敍上の計算式よりさらに大きな熱伝導率をうる 材料の組合せを予想しらる。たとえば銅球をアルミニウ ムでろ5付けできれば $90 \mathrm{kcal} / \mathrm{m} \cdot \mathrm{hr} \cdot{ }^{\circ} \mathrm{C}$ 以上の $k_{*}{ }^{\circ} か$ えられよう。

参考例として，他にラシヒリング充填物を用いた場合 です案外 $k_{0}{ }^{\circ}$ が小さくならず現在 $4 \sim 30 \mathrm{kcal} / \mathrm{m} \cdot \mathrm{hr} \cdot{ }^{\circ} \mathrm{C}$ の範围の値を得ている。総しててこの層は当初の予想を はるかに上回った $k_{*}^{0}$ を有していたといえる。

\section{6. 結 語}

金属棒の熱云導度测定法々同様の方法を用い, 万5付 け充填層の垂直方向の静止時有効熱层導度を測定した。

この場合，乃5付け充填層の構造を破壊したときの接 着架橋切口の所見によりこのような球充填の場合 $k_{0}{ }^{0}$ に方向性はないよ5に考えられる。

ついで $k_{\bullet}{ }^{\circ}$ の理論的推定の提案を行なった。すなわち， はしめ 2 球のろ5付けされた状態の熱抵抗を計算し,つ いで云熱经路の曲折程度を表わすために径路俰数なる概 念を導入し，数種の規則的充填構造を用いて，空間率と 径路俰数の間值線関倸があることを見出し，充填の際 の空間率から，そのときの径路係数を推定しつきの理論 式をえた。

$$
k_{q}^{0}=(1-\varepsilon) \cdot \frac{3}{\alpha \Omega} \cdot k_{p}
$$

実験値および理論的推定値を Table 1 に示す。両者は 極めてよい一致を示した。

終りに本研究を行ならにあたり，御助言を賜わった永题登 教投ならびに東京工莱大学の方々に厚く謝意を表する。

\section{Nomenclature}

$A$ : area through which heat flows at right angles $\left[\mathrm{m}^{2}\right]$

$a^{2}$ : connected area ratio of spherical packing by soldering (connected area $\left./ 4 \pi r^{2}\right)[-]$ $c:$ carbon content

$D_{p}:$ diameter of particle

$k, k_{\mathrm{Fe}}, k_{\mathrm{Cu}}, k_{\mathrm{b}}, k_{\mathrm{p}}$ : thermal conductivity of metal, iron, cupper, bridge part in soldered packed-bed, and particle

$\left[\mathrm{Kcal} / \mathrm{m} \cdot \mathrm{hr} \cdot{ }^{\circ} \mathrm{C}\right]$

$k_{0}:$ effective thermal conductivity

$\left[\mathrm{Kcal} / \mathrm{m} \cdot \mathrm{hr} \cdot{ }^{\circ} \mathrm{C}\right]$

$k_{\bullet}^{0}, k_{\bullet}{ }^{\prime \prime}$ : stagnant effective thermal conductivity

$\left[\mathrm{Kcal} / \mathrm{m} \cdot \mathrm{hr} \cdot{ }^{\circ} \mathrm{C}\right]$

$q$ : heat flux

[Kcal $/ \mathrm{hr}]$

$r$ : radius of particle

[m]

$R, R_{b}, R_{p}, R^{\prime}:$ thermal resistance of model, bridge part in soldered packed-bed, particle and soldered packed-bed

[hr $\left.{ }^{\circ} \mathrm{C} / \mathrm{Kcal}\right]$

$V, V_{\text {of }}:$ volume and effective volume $\left[\mathrm{m}^{3}\right]$

$X$ : effective radius of packing [m]

$\alpha, \alpha^{\prime}$ : effective path length coefficient $[-]$

$\delta_{q}$ : increment of heat flux [Kcal/hr.]

$\varepsilon$ : void fraction $[-]$

$\lambda: k_{b} / k_{p} \quad[-]$

$\theta_{0}$ : effective angle corresponding to the bridge part of neighbor two spheres

[radiun]

$\Omega$ : thermal conduction parameter of soldered packed-bed

\section{Literature cited}

1) Takeoka, S. and Nagasako, N.: Chem. Eng. (Japan). 25, 588 (1961)

2) van Dusen u. Shelton: Bur. Stand. J.Res., 12, 429 (1934)

3) Kling, G.: Forsch. Gebiete Ingenieurw., 9, 28 (1938)

4) Wilhelm, R. H., Wynkoop, W. C. and Collier, D. W. : Chem. Eng. Prog., 44, 105 (1948)

5) Argo, W. B. and Smith, J. M. : Chem. Eng. Prog., 49, 1977 (1953)

6) Yagi, S. and Kunii, D.: Chem. Eng. (Japan), 18, 578 (1954)

7) Kunij, D. and Smith, J. M. : A. I. Ch. E. Journal, 6, 71 (1960)

8) Schotte, W.: A. I.Ch. E. Journal, 6, 63 (1960)

9) Sugiyama, S. and Fujitzu, M. : Chem. Eng. (Japan), 24, 12 (1960)

10) "Kagaku-Kögaku-Benran", p.120 (1950)

11) Yagi, S, Yamazaki, Y. and Ishji, M. : Chem. Eng. (Japan), 21, 426 (1957) 